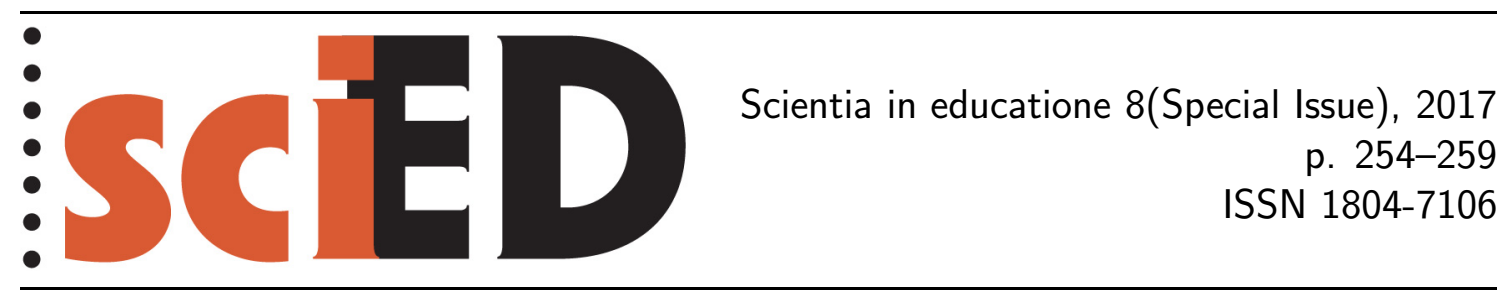

\title{
Informal Teaching of Special Theory of Relativity
}

\author{
Jindřiška Svobodová, Jan Novotný, Jana Jurmanová
}

\begin{abstract}
In the present Case Study we explore the comprehension levels of relativity theory in prospective science teachers who take the introduction to physics lesson at the Faculty of Education. Special Theory of Relativity multimedia animation was used to illustrate basic relativistic consequences. The effect of it for learning was researched. In the research, a case study was used. Research data were obtained by interviews and using open-ended questions prepared by the researcher.
\end{abstract}

Key words: informal science education, animation, courseware, special relativity. 


\section{INTRODUCTION}

Nowadays Special Theory of Relativity (STR) is important for our understanding of time, space, matter and energy. It represents an example of creative and analytical thought. Although some of the consequences of the basic ideas may seem intuitive, there are various pitfalls no only for beginners. Many students are looking forward to lessons of STR. They often have high expectations for this topic, but soon they turn that the understanding STR is quite difficult task in practice. Every physicist probably had met with STR insistent critics who claim that STR leads to the absurdities. Physics teacher should be able to vindicate the theory at least for himself (because an effort to convince is usually fruitless). This ability to oppose the critique represents a real touchstone in understanding STR.

When the STR is taught in schools, it is not possible to carry out real experiments. We have prepared several multimedia animations giving a brief overview of relativity as stand alone content files. These short animations were complemented by various questions and problem tasks and were presented to students.

The aim of our study was to find indications and patterns which can help an understanding starting points of the theory of relativity (Geršl et al., 2006).

For research purpose we decided to realize a Case Study focused on student's reading, math, science skills and creative abilities to solve problems. In spite of an increasing availability of animations for science education, there has been little research into the value of animations in science teaching. Stith (2004) has reviewed this issue with a focus on cell biology teaching animations. A review of the literature covering all educational disciplines has indicated that there are certain parameters that need to be considered when making a teaching animation (Tversky \& Morrison, 2002).

\section{STR Flash ANimations}

The textbook "Special Theory of Relativity 2005" is available as downloadable PDF course material for students was prepared several years ago (Geršl et al., 2006; Geršl, Jurmanová \& Novotný, 2006). This textbook is still quite popular among physics students and teachers. The carefully structured text and number of explanations make that educational material is suitable for a self-study.

The authors have developed set of cartoon-style multimedia animations illustrated STR. Since this year there is an independent access for animations. We offer free streaming animated files as well as commentary text (this time in Czech only) with a written explanation, all of which explore the STR realm (Svobodová, 2013). The production altogether was simply titled The Cartoon Guide to Relativity.

Every animation is narrative, combining story-telling and visualization. Theory and experiments are appearing on background story. The story begins meeting an Alien (from an advanced civilization that STR applied in everyday practice) and Professor of theoretical physics. Alien traveling at high speed rocket informs Professor of his observations. All measurements and observations of natural phenomena are based on determining the spatial and temporal relations. The main characters Alien and Professor are guides through all manifestations of STR ideas that are away from common sense. The processes in space-time are described from point of view of different frames of reference (we restrict ourselves on inertial systems of reference). 
The following thematic sections are available:

- The Basic Science Terms.

- Time Synchronization.

- Adding velocities.

- Time Dilatation.

- Length Contraction.

- Twin Trip.

Much of the material was prepared at level suitable for high school students. This approach is designed for those students who desired better understanding the STR. Students can clarify special relativity terminology in conversation between Alien and a Professor and they can compare their ideas to the processes modeled in animation.

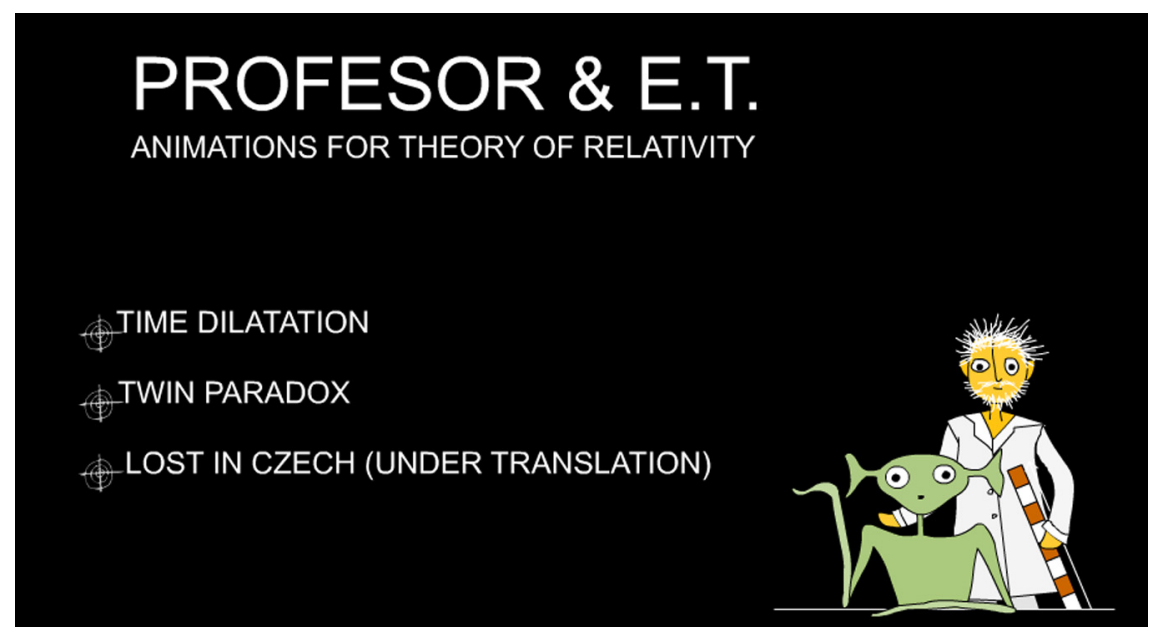

Figure 1: Internet portal design

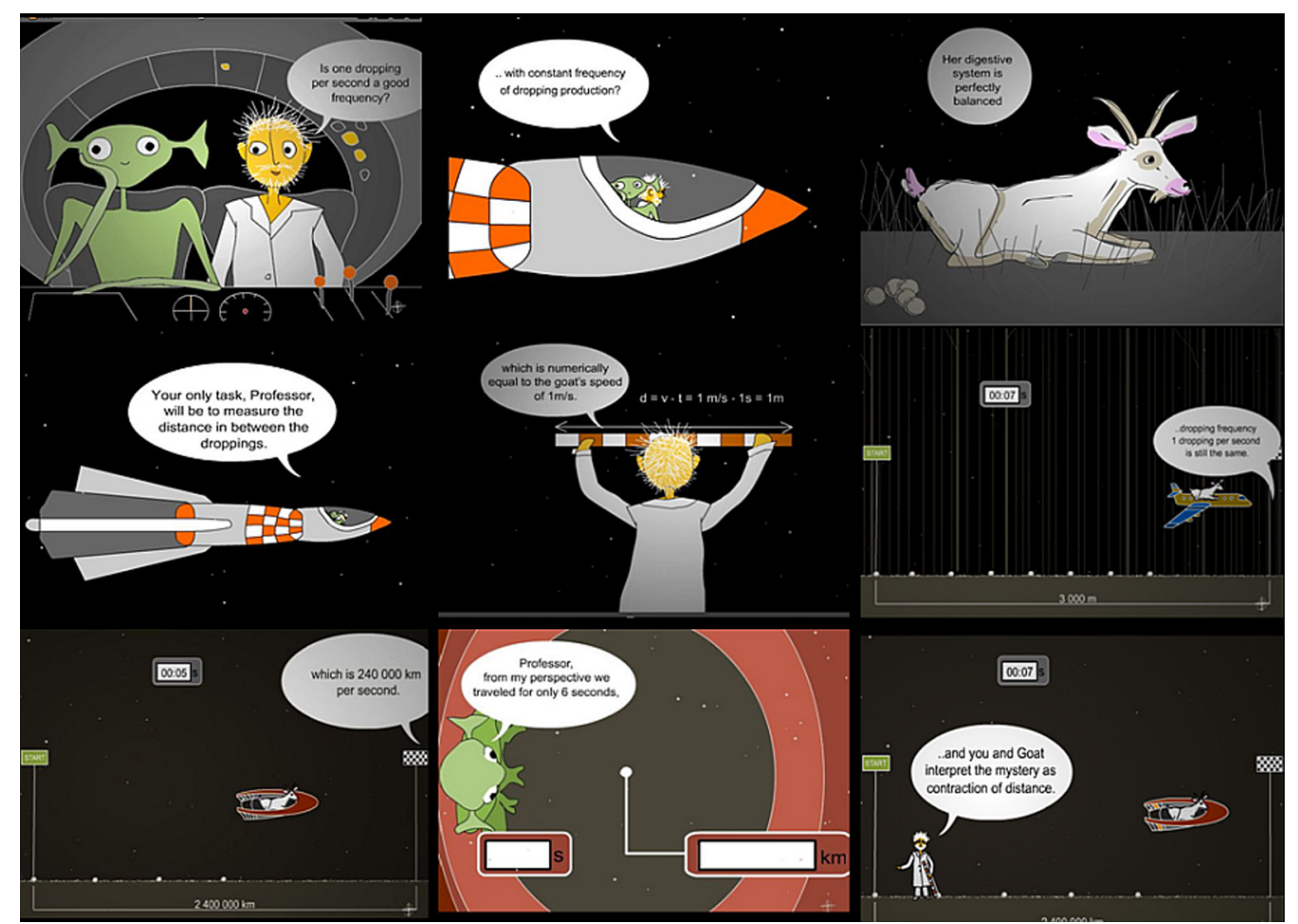

Figure 2: Sample captions of the STR animation 


\section{The Research Design}

The primary goal of our case study was to determine whether the results of students who saw the animation are different from other. We wanted to find out how the observation of animations affects student's approach to perform their solution of requested tasks.

We were looking for factors that could enhance the learning process of STR. From written tests inspired Hewitt (2011), Sherr (2001) we could evaluate student's knowledge and skills and we could identify an incomplete treatment in areas that may prevent from misunderstandings in STR concepts. Test questions were intentionally assigned more generally. Test assignment was designed so that it examined the prerequisites of math, geometry and graphics. Figure 3.

\section{Sample Questions and Tasks}

Is the nonsimultaneity of hearing thunder after seeing lightning
similar to relativistic nonsimultaneity?
Firecracker $A$ is 300 m from you, firecracker $B$ is $600 \mathrm{~m}$ from you in the same
direction, You see both explode at the same time.
Define event $A$ to be "firecracker $A$ explodes" and event $B$ to be "firecracker $B$
explodes".
Does event $A$ occur before, after or at the same time as event $B$ ?
Event A occurs at spacetime coordinates ( $300 \mathrm{~m}, 2$ us).
Event B occurs at spacetime coordinates (1200m, 6us).
Could A possibly be the cause of B?
Event C occurs at spacetime coordinates (2400m, 8us).
Could A possibly be the cause of C?

Figure 3: Test questions example

Moreover, we have used the case study research method. The advantage of case study methods is that it provides detail information about a particular case. This helps to set the groundwork for future strong studies. The Case Study is an empirical inquiry allows a rich exploration of student perceptions into common situations.

The research questions we were set: What indicators are changed after student's observation of cartoon animation? Is there a relationship between graphical and geometrical competence and ability to solve the set of tasks? Does the student's ability to clearly formulate their own approach affect the result of test?

\section{The Case Study method Study Design 2013}

Participants were university students, mostly future physics teachers. 16 students attending university physics course took part in the study. They fulfilled given test (a set of 15 tasks) in sufficient time.

Students were divided into 2 groups: AA students were shown an animation before their test work, the other group NA only wrote a test without any animation. After that interviews for each student about their worksheets were audio recorded. Records were transcribed and coded. The method of categorization into indicators emerged during the analysis of records. We recombine data to address the initial purpose of the study. In several cases a short interview to gather additional data to verify key observations was necessary. 
These observed symptoms and indicators were selected: careful reading, initial acceptance of the task (without any intervention), a clarity in student's explanation, an ability to reformulate task by own words, adequacy of graphic representation, use knowledge of STR, transfer of knowledge and skills from math, geometry and other disciplines, value judgment — a solution based on reasoning, limitation of own approach, creativity, success in task solution, ability to focus and maintain attention.

\section{RESULTS}

The outputs are charts and brief descriptions of detected remarkable answers. Several graphs were constructed for comparative analyses. The graph shows (Figure 4) the different distribution of "performance" indicators for the first (AA) and the second (NA) group.

We can see that the most differences are in the categories of knowledge use STR (although most of these tasks and questions don't require knowledge STR) transfer of knowledge from different disciplines and creativity. The length of red arrows (Figure 4) corresponds to increase of the indicator. Shift is in transfer of knowledge from different disciplines and for creativity. The first group shows greater courage to accept tasks and has a better ability to reformulate task in own words. They were more successful in solution tasks.

The comparison of both groups indicates that the influence of fun animations is significant in the majority of items. The most pronounced influence is in indicator transfer of knowledge.
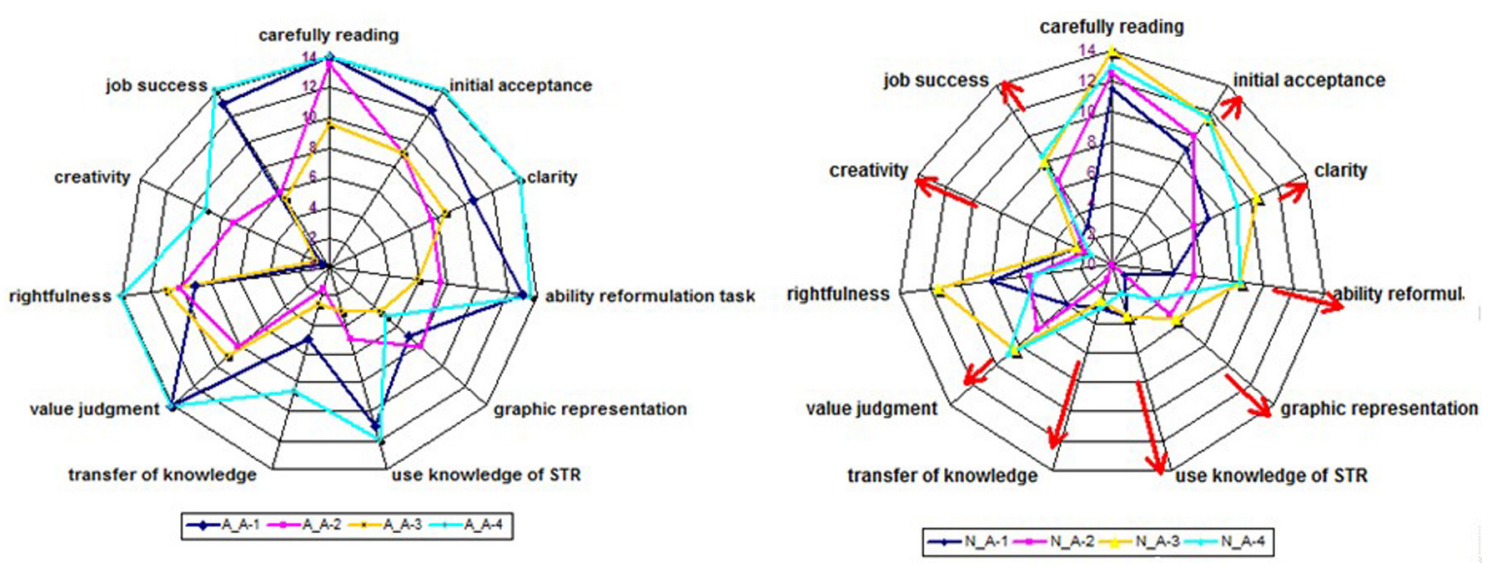

Figure 4: Graphic comparison of both groups

The content analysis of the answers (for example Figure 3) reveals that: students meet difficulties in grasping the relativity of motion and in using the frames of reference properly, several students didn't seem to be able to answer the question about the speed of light.

\section{CONCLUSiOnS}

The students, who have undertaken STR cartoon multimedia stories, have reported shifts in values our indicators. Students have demonstrated more enthusiasm for the subject matter and they results were better. We can conclude that viewing animation is certainly not a wasting time in the classroom. 
The STR Animations website provides the animations as downloadable, reusable, learning objects that teachers can use however they like. In further refinement of improved cartoon animations, authors will work on suggested worksheets and instructor notes.

Next research is now focusing on deeper analysis of the student's concept development when experimenting with STR animation.

\section{ACKNOWLEDGEMENT}

Support for this study has been provided by EP project OPVK Moduly jako prostředek inovace v integraci výuky moderní fyziky a chemie reg. č.: CZ.1.07/2.2.00/ 28.0182 .

\section{REFERENCES}

Hewitt, P. G. (2011). Conceptual Physics, 11th edition. Boston: Addison-Wesley.

Jurmanová, J., Novotný, J. \& Geršl, J. (2006). Úvod do speciální a obecné teorie relativity [CD-ROM]. České Budějovice: Scientific Pedagogical Publishing.

Novotný, J., Jurmanová, J., Geršl, J. \& Svobodová, M. (2006). Základy teorie relativity. Brno: Masarykova univerzita.

Novotný, J. \& Svobodová, J. (2013). 10th International Conference On Hands on Science, Educating for Science and through Science.

Sherr, R.E. (2001). An investigation of student understanding of basic concepts in STR [Dissertation thesis]. University of Washington.

Svobodová, M. (2013). STR Cartoon Project Website. Available at http://www.ped.muni.cz/wphy/C_R/

Stith, B. J. (2004). Use of animation in teaching cell biology. Cell Biol. Educ., 3, 181-188.

Tversky, B. \& Morrison, J. B. (2002). Animation: can it facilitate? Int. J. Hum. Comput. Stud., 57, 247-262.

JINDŘIŠKA SVOBODOVÁ

JAN NOVOTNÝ

Faculty of Education, Masaryk University, Brno, Czech Republic

JANA JURMANOVÁ

Faculty of Science, Masaryk University, Brno, Czech Republic 